\title{
Awareness on Health Problems Among Business Process Outsourcing Employees- A Survey
}

\author{
Lasya Genji', Gayathri. R² and Vishnu Priya. V³ \\ ${ }^{1}$ Saveetha Dental College and Hospitals, Saveetha Institute of Medical \\ and Technical Sciences, Saveetha University, Chennai, India \\ ${ }^{2}$ Associate Professor, Department of Biochemistry, Saveetha Dental college and Hospitals, \\ Saveetha institute of Medical and Technical Sciences, Saveetha university, Chennai,India. \\ ${ }^{3}$ Professor, Department of Biochemistry Saveetha Dental College and Hospitals \\ Saveetha Institute of Medical and Technical Sciences, Saveetha University, \\ Chennai, India
}

\section{ABSTRACT}

Business process outsourcing (BP0) is at present suffering high consistent misfortune which is offering a disturbing hint to many outsourcing associations. BPO is the one division where we can discover an increasing number of workers turnover for different reasons. India in the ongoing years has indicated enormous advancements in the zones of communication, power and programming improvements. In spite of this, the business has ordinarily made more worry among its workers, letting them to confront a great deal of physical, mental and moral related issues.This was a survey conducted in an online forum,survey planet. It was a questionnaire based survey. A set of 10 questions to assess symptoms of health problems faced by business process outsourcing employees. The results were obtained and statistically analysed through SPSS software, chi square test was done to check the association and a p value of 0.05 was said to be statistically significant. The survey was conducted in the month of May, 2020.44\% of the total study population preferred the job due to its less qualification criteria and frequent headache is the most common problem encountered by the employees. Males suffered with more health problems than females. The study mainly focuses on various health problems experienced by outsourcing employees.

KEY WORDS: BPO (BUSINESS PROCESS OUTSOURCING), HEALTH PROBLEMS, EMPLOYEE ISSUES, HEALTH RELATED STRESS.

\section{INTRODUCTION}

The Business Process Outsourcing (BP0) industry was set up in India just over the most recent 15 years and is

\section{ARTICLE INFORMATION}

${ }^{*}$ Corresponding Author: gayathri.sdc@saveetha.com Received 23rd July 2020 Accepted after revision 27th Sep 2020 Print ISSN: 0974-6455 Online ISSN: 2321-4007 CODEN: BBRCBA

Thomson Reuters ISI Web of Science Clarivate Analytics USA and Crossref Indexed Journal

\section{Clarivate
Analytics}

NAAS Journal Score 2020 (4.31) SJIF: 2020 (7.728)

A Society of Science and Nature Publication,

Bhopal India 2020. All rights reserved.

Online Contents Available at: http//www.bbrc.in/

Doi: http://dx.doi.org/10.21786/bbrc/13.8/192 quickly extending. The evaluated turnover of the BPO division by March 2008 was around US $\$ 10.9$ billion (Kshetri and Dholakia, 2009). BP0 is regularly sorted as back office outsourcing, which includes inside business capacities, and front office outsourcing, client related administrations. The workers at the call community need to tune in, watch, and talk all the while without a break. Whimsical working hours alongside stationary employment that requests sitting on a seat for extended periods every day, perusing prescripted discussions on the telephone unendingly may bring about musculoskeletal and psychologic strain. Long working hours, lasting night shifts, absence of social and family connections, 
unbelievably high work targets, loss of personality, combined with high extra cash at a youthful age may incline the BPO representatives to various types of reliance, including tobacco (Sudhashree, Rohith and Shrinivas, 2005).

Recent years have seen an enormous and developing population of talented youthful experts working in generally new fields like IT-ITES explicitly ITES or business process outsourcing (BPO) enterprises (Kesavachandran et al., 2006). These fields request odd working hours and continuous move changes. The impact of these on typical working of the human body is a field that is frequently overlooked. NASSCOM's overview demonstrates that around 4.5 million representatives are working in BPO and related areas. Sixty-five percent of the workers in the BPO industry are guys (Cruse et al., 2001). Long working hours, whimsical timings, long travel time, work pressure, and lacking breaks have consistently been the components causing worry among the BPO representatives. Any normal BPO representative places in 11-12 hours of work for every day and on occasion it arrives at 14 hours if there should be an occurrence of organizations that encourage additional time.

Changes of sharpness and subjective effectiveness have been recommended in individuals whose circadian rhythms are disturbed, for e.g., night or shift workers (Rouch et al., 2005). Many examinations have revealed an assortment of unfavorable natural, mental, and social impacts of shift work and other atypical work routines on the workers. For example, consequences for a wide arrangement of wellbeing and prosperity segments have been watched, including rest, eating, conduct, neuropsychic and cardiovascular capacities, menstrual cycle, work mishaps, non-attendance, and many others (Costa, 1996). Long working hours, lack of sleep, sporadic dietary propensities, and so forth., which are basic to these businesses may negatively affect subjective execution in typical human beings (Elovainio et al., 2009).

Despite the fact that tobacco is seriously harmful to wellbeing, its utilization is generally pervasive in all the areas of Indian culture. As per the consequences of the National Family Health Survey-3 (NFHS-3) led in 20052006 in which enquiries on tobacco use were surveyed in women and men, in the age groups between 15-19 years and 15-54 years, individually, the commonness of tobacco utilize was 57\% among men and 10.8\% among women. Women commonly used smokeless types of tobacco (Chawla and Sondhi, 2011).

The aim of the present study is to create awareness on the health problems encountered by BPO employees in india. Although much has been discussed the enormous open doors made by the BPOs in the developing countries, very little has been expressed in regards to the difficulties looked by these associations, especially as to the wellbeing and security given that are extraordinarily to this new and creating segment. Tending to these issues and making a solid workplace would be a success win circumstance for the two businesses and representatives.

Table 1. Age and Gender distribution of study population.

\begin{tabular}{|l|c|c|}
\hline & $\begin{array}{c}\text { Number of } \\
\text { participants }\end{array}$ & Percentage \\
\hline Gender & & \\
\hline Male & 29 & $58 \%$ \\
\hline Female & 21 & $42 \%$ \\
\hline Age & & \\
\hline 20-30 years & 30 & $60 \%$ \\
\hline 31-40 years & 20 & $40 \%$ \\
\hline
\end{tabular}

Figure 1: Pie chart showing frequency and percentage distribution of reasons for choosing business process outsourcing as a job. Brown colour denotes participants who did not get a better job, grey denotes participants who preferred business process outsourcing job due to its good environment, light yellow colour denotes participants who preferred the job due to its less qualification criteria, and navy blue colour denotes the participants who preferred the job due to attractive lifestyle. The most common reason for choosing the job was due to its less qualification criteria (44\%).

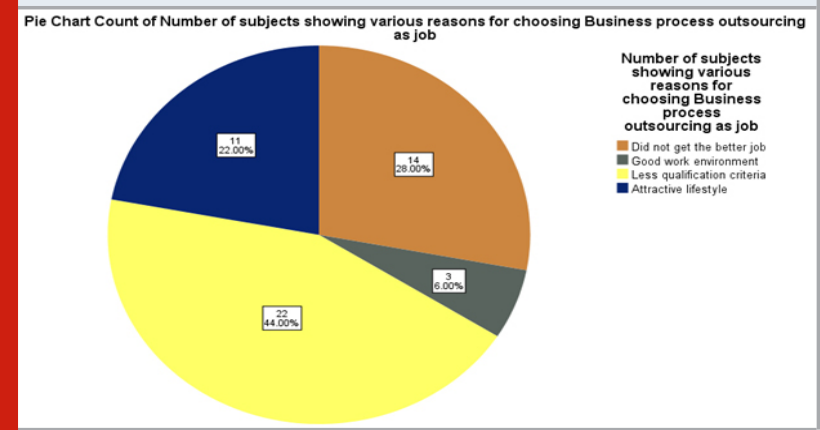

\section{MATERIAL AND METHODS}

This study was conducted in an online setting. A sample size of 50 participants who are working in the business process outsourcing sector of different age groups and gender took part in the survey. Ethical approval was given by the Institutional Review Board. The study was designed to analyse health problems encountered by BPO employees. The questionnaire consists of selfstructured standard questions pertaining to the health problems commonly experienced by BPO employees. The questionnaire was circulated through an online survey portal. Measures are taken to minimise bias by randomisation of parameters. Questions are pretested. Homogenisation and replication of experiment and cross verification with existing studies were done to improve the quality of the study. The necessary data which included gender, age, impact on quality of life, various 
health problems were obtained from the responses and subjected for further analysis. Statistical analysis was performed using SPSS software version 23.0 and Chi square test was used to compare differences between gender and age to find correlation.

\section{RESULTS AND DISCUSSION}

The study sample consisted of 50 BPO employees, about $58 \%$ of the participants were male and $42 \%$ were females. Among 50 participants, $60 \%$ of the population belonged to age group between $20-30$ years and $40 \%$ of the population belonged to age group between 31 to 40 years (Table 1). The reasons for choosing BPO jobs are due to its less qualification criteria (44\%), followed by attractive lifestyle (22\%), and $28 \%$ of the participants did not get a better job and 6\% of the population opted for this job due to a good work environment (Figure 1).

Figure 2: Pie chart showing frequency and percentage of various health problems experienced by the participants due to their job. Light blue colour denotes participants who experienced frequent headache, red colour denoted participants with anger management issues, green colour denotes participants with anger management issues along with frequent headaches, orange colour denotes participants with anger management issues along with eye problems, dark yellow colour denotes participants with anger management issues along with menstrual problems, etc.. The most commonly encountered health problem in the study population is participants frequently experiencing headache $(44 \%)$.

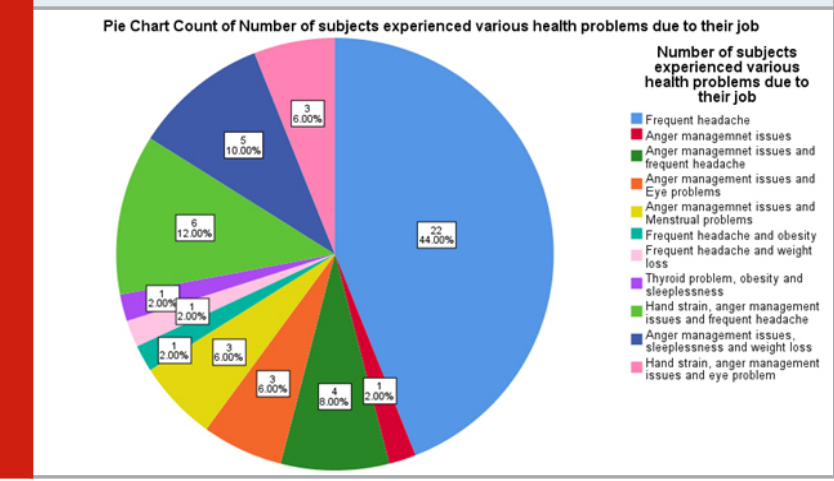

The various health problems encountered by the BPO employees are frequent headache(44\%) followed by combination of health problems like hand strain, anger management issues and frequent headache(12\%), anger management issues, sleeplessness and weight loss (10\%), anger management issues and frequent headache (8\%), anger management issues and menstrual problems along with eye problems in $6 \%$ of the population and equal percentage of $2 \%$ is accounted for health problems like anger management issues, frequent headache along with obesity, frequent headache along with weight loss,and thyroid problem along with obesity and sleeplessness (Figure 2). The association between gender and various health problems encountered by BPO employees when analysed it showed male predilection with a $\mathrm{p}$ value
.288 which is statistically not significant (Figure 3). The correlation between gender and various health problems encountered by the BPO employees when analysed showed that higher incidence of health problems is more in the age group between 20 to 30 years.

Figure 3: Barchart shows the association between gender and various health problems experienced by the business process outsourcing employees. $\mathrm{X}$ axis represents gender and $\mathrm{Y}$ axis represents number of subjects experiencing various health problems due to their job. Light blue colour denotes participants who experienced frequent headacheThe incidence of health problems was more in males than females. Where the majority of both males and female participants suffered headache. Chi square test was done and association was found to be statistically not significant. Pearson chi square, $p$ value $=.288$ ( $p>0.05$ statistically not significant).

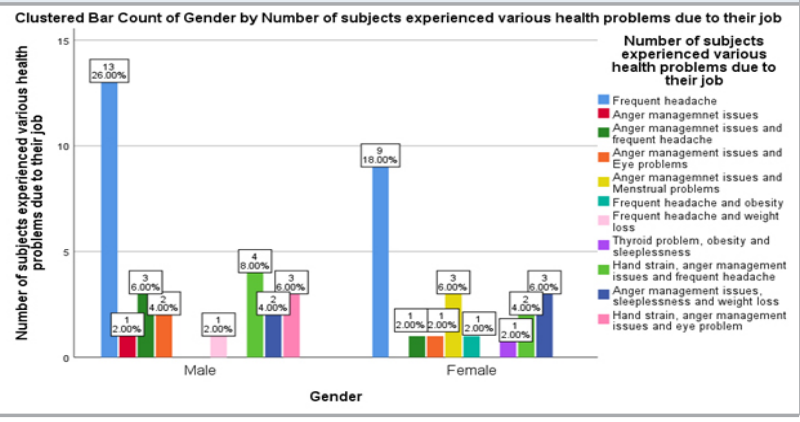

Figure 4: Barchart shows the association between age and various health problems experienced by the business process outsourcing employees. $\mathrm{X}$ axis represents age and $\mathrm{Y}$ axis represents number of subjects experiencing various health problems due to their job. Light blue colour denotes participants who experienced frequent headache. The incidence of health problems was more in age group between 20 to 30 years than in age group between 31 to 40 years.Majority of 20-30 years old suffered from headache. Chi square test was done and association was found to be statistically not significant. Pearson chi square, $p$ value $=.246$ ( $p>0.05$ statistically not significant).

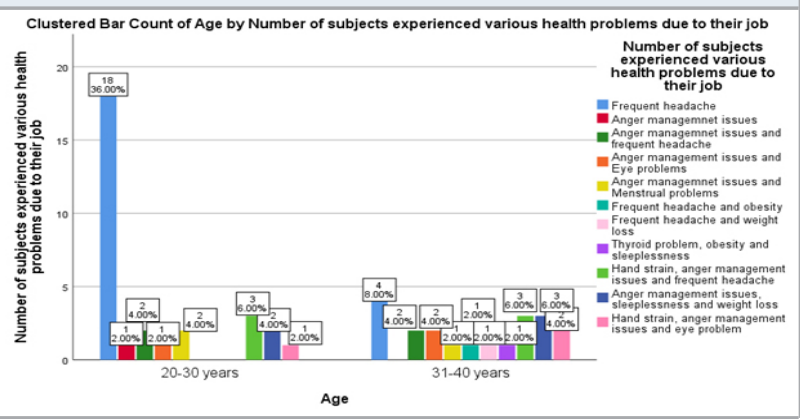

In the present study the main reason for opting BPO jobs are due to its less qualification criteria. The evolving ways of life (20\%), demand for luxury, high paid salary for the employees with less qualification (40\%) are the main reasons for the young graduates to choose the business 
process outsourcing jobs (Chavan and Potdar, 2011) this study was conducted in India by Chavan is in consensus with the present study. However, another study stated that a good work environment is the major criteria for choosing BPO jobs by the youth (Insha, Rodrigues and Chavan, 2018) (Suri and Rizvi, 2008). This could be due to the fact that surveys are conducted in different geographic locations which lead to the differences to the present study. The study conducted in Delhi showed that $30 \%$ of the participants of their study opted for the BPO jobs due to the reason that participants did not get a better job of their desire leading to the preference of BPO jobs, the frequencies of the present study goes in hand with the previous literature (Suri et al., 2007).

The study reveals that various health issues encountered by BPO employees are hand injury, frequent headaches, eye problems, weight loss, sleep deprivation , obesity, menstrual problems, thyroid problems. Among all, headache is most commonly experienced by the BPO employees in this study. In the previous studies the medical history of BPO employees showed predominance of musculoskeletal problems followed by headache, sleep problems, eye problems have been the common health issues among the BPO employees in association with gender males(70\%) are more affected than females(40\%) (Suparna, Sharma and Khandekar, 2005) (Moher, Hey and Lancaster, 2005) . This may be due to the fact that the study population showed that males population is higher in the BPO sector when compared to the females which is similar to the present study.The age of employees in BPOs with high incidence of health problems in other studies varied between 22-30 years (Kesavachandran et al., 2006) (Shah, Reddy and Hegde, 1999) , which is in support to the present study.

In this survey the limitations included due to less quantitative data. Geographic limitations of the survey which are limited only to the South Indian population. In future study can be done involving a large number of participants from different ethnicities for better results. Research should focus on improving quality and addressing new questions such as mechanism, developmental time factor and relevance of risk factors. Thus the survey serves as evidence and adds to the consensus.

\section{CONCLUSION}

Within the limitations of the study, we can conclude that 44\% BPO employees had frequent headaches followed by combinations of health problems. Males are prone to have more health problems than females in the BPO sector and the most commonly affected age group is between 20 to 30 years. BPOs are very interested in earning huge money with a lot of strain in the work and the most common reason in preferring BPO jobs where less qualification criteria being the main reason. Awareness on health education, preventive and creative measures has to be taken to overcome health problems.

\section{ACKNOWLEDGEMENTS}

The author would like to thank the study participants for their participation and kind cooperation in the study.

Author Contributions: Author 1 (Lasya Genji), carried out the survey collecting data and drafted the manuscript after performing the necessary statistical analysis. Author 2 (Dr. Gayathri.R) aided in conception of the topic, has participated in the study design, statistical analysis and has supervised in preparation of the manuscript.

Conflicts of Interest: None declared.

\section{REFERENCES}

Chavan, S. R. and Potdar, B. (2011) 'A critical study on work-life balance of BPO employees in India', in International Conference on Technology and Business Management, pp. 966-977.

Chawla, D. and Sondhi, N. (2011) 'Assessing the role of organizational and personal factors in predicting turn-over intentions: A case of school teachers and BPO employees', Decision (0304-0941), 38(2). Available at: https://bit.ly/3iRDFRT

Costa, G. (1996) 'The impact of shift and night work on health', Applied ergonomics, 27(1), pp. 9-16.

Cruse, S. M. et al. (2001) 'Smoking cessation in the workplace: results of an intervention programme using nicotine patches', Occupational medicine, 51(8), pp. 501-506.

Elovainio, M. et al. (2009) 'Cumulative exposure to high-strain and active jobs as predictors of cognitive function: the Whitehall II study', Occupational and Environmental Medicine, pp. 32-37. doi: 10.1136/ oem.2008.039305.

Insha, M., Rodrigues, D. E. and Chavan, K. R. (2018) 'Study to assess the health issues among employees working in selected call centres of Mangalore', Journal of Drug Delivery and Therapeutics, 8(6), pp. 58-61.

Kesavachandran, C. et al. (2006) 'Working conditions and health among employees at information technology-enabled services: a review of current evidence', Indian journal of medical sciences, 60(7), pp. 300-307.

Kshetri, N. and Dholakia, N. (2009) 'Professional and trade associations in a nascent and formative sector of a developing economy: A case study of the NASSCOM effect on the Indian offshoring industry', Journal of International Management, pp. 225-239. doi: 10.1016/j. intman.2008.09.003.

Moher, M., Hey, K. and Lancaster, T. (2005) 'Workplace interventions for smoking cessation', Cochrane database of systematic reviews , (2), p. CD003440.

Rouch, I. et al. (2005) 'Shiftwork experience, age and cognitive performance', Ergonomics, 48(10), pp. 1282-1293. 
Shah, P. B., Reddy, P. S. and Hegde, S. C. (1999) 'Stress: Occupational health disorder amongst computer professionals', Indian J 0ccup Health, 3, pp. 71-73.

Sudhashree, V. P., Rohith, K. and Shrinivas, K. (2005) 'Issues and concerns of health among call center employees', Indian journal of occupational and environmental medicine. Medknow Publications, 9(3), p. 129.

Suparna, K., Sharma, A. K. and Khandekar, J. (2005) 'Occupational health problems and role of ergonomics in information technology professionals in national capital region', Indian journal of occupational and environmental medicine. Medknow Publications, 9(3), p. 111.

Suri, J. C. et al. (2007) 'Sleep patterns and their impact on lifestyle, anxiety and depression in BPO workers', Indian J Sleep Med, 2. Available at: https://bit.ly/2Gyz7Tk Suri, S. and Rizvi, S. (2008) 'Mental health and stress among call center employees', Journal of the Indian academy of applied psychology. Indian Academy of Applied Psychology, 34(2), pp. 215-220. 